\title{
報文の使い方 環状充壃層な.ど複雄な型式における伝熱*
}

前田四郎**

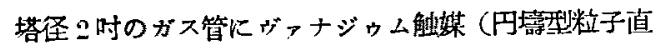
径 $6 \mathrm{~mm}$ ）を $25 \mathrm{~cm}$ の高さに充買し 5.97 モ\% $\mathrm{SO}_{2}$ と 空気との混合物を壁と同一温度まで加熱して通して $\mathrm{SO}_{2}$ の酸化を行っている。些気を $3.93 \mathrm{~kg} / \mathrm{hr}$ で通し, $480^{\circ} \mathrm{C}$

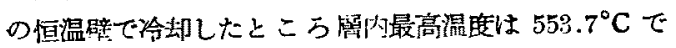

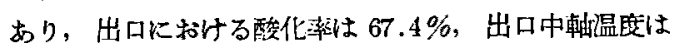
$548.4^{\circ} \mathrm{C}$ であった。(文献 (8) Tab. $7 \cdot 1$ exp. No. 101)

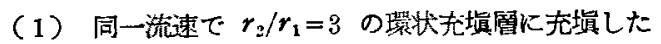

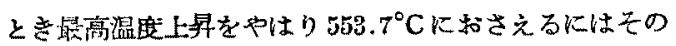
大きさいかか。

（2）管中心距陮が淔径のコ倍である多管熱交換刑光 增畨（管外充䖯）においてはいかか。

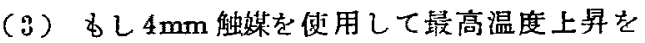
$520^{\circ} \mathrm{C}$ におさえ，かつ同一収率をあげたいときには塔径

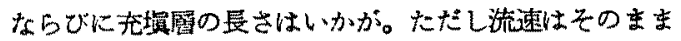
とし活性齐ルギー $\mathrm{A}=11500 \mathrm{cal} / \mathrm{g}-\mathrm{mol}$ とす。

【解】文献 (2)，(3) を参照してます的筒の場合の $K$ の值, および各愁の基礎的数值を計算する。

$\mathrm{SO}_{2}$ の流感汒

$3.93(64 / 29) \cdot(5.97 / 94.03)=0.551[\mathrm{~kg} / \mathrm{hr}]$ ゆ光に全ガス流量 $W[\mathrm{~kg} / \mathrm{hr}]$ (原報では $G$ ) は

$W=3.93+0.551=4.48[\mathrm{~kg} / \mathrm{hr}]$

次に $\left(c_{p} \Delta t / Q\right)_{\max }$ を計算して図より $K$ を求める。 触媒層内に和ける反応山，

$2 \mathrm{SO}_{2}+\mathrm{O}_{2}=2 \mathrm{SO}_{3}+2 \times 22600$

出口平均温度を簢単のため $480+(548.4-480) / 2=$ $514.4^{\circ} \mathrm{C}$ とすれば反応平衡値は 0.946 である。したが って䧳位重量の原がスが平衡に達するまでの発熱量 $Q$ は

$Q=-\frac{22600(0.946)}{(29)(94.03) /(5.97)+64}=41.1[\mathrm{kcal} / \mathrm{kg}$-全ガス] $c_{p}$ として筀気の值をとると $c_{p}=0.245[\mathrm{kcal} / \mathrm{kg}]$ 題意火上り $(\Delta t)_{\text {max }}=(558.7-480)=73.7^{\circ} \mathrm{C}$ 付えK $\left(c_{p} \Delta t / Q\right)_{\max }=(0.245)(73.7) / 41.1=0.44$ この $\left(c_{p} \Delta t / Q\right)_{\max }$ K対する $K$ の值は交献 (4) Fig. 5 より円筒型充㙞風 (破線) に対して $K=4.0$ をうる。 因みに出口反応率より $K$ を求めてみる。反応深は題

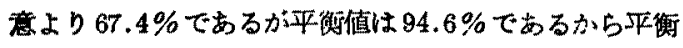

* 昭和30年 2 月10日受理

***䍒北大学工学部店用化学科
值に対する反応迋成㜪は

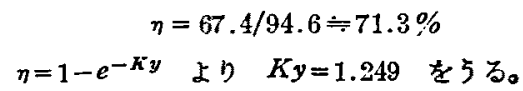

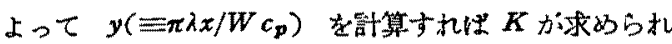
る。

$y$ を計算するには， $\lambda, x, W, c_{p}$ を求めねばならな

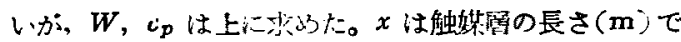

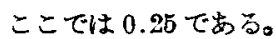

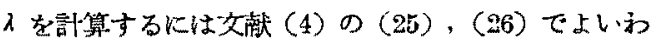
けであるが、この螌媒性交献(3)に示したようにこれら の値より $10 \%$ 低し值としてえら机う。

このガスの粘㢃 $\mu$ は加成法より

$\mu=0.036(0.9403)+0.081(0.0597 .=0.0857$ [c.p.]

よってレイルズ数 (Re)は

$R e={ }_{\mu}^{d u p}=\frac{(0.006)(4 / \pi)(4.48) /(0.0529)^{2}}{3.6(0.0557)}=94.7$

中去に $\lambda / k=1.72(R e)^{0.41}(0.9)=10.06$

$\lambda=10.06(0.046)=0.463$

ゆ兑に

$$
y=\frac{\pi \lambda x}{W c_{p}}=\frac{(3.14)(0.463)(0.55)}{(4.48)(0.245)}=0.381
$$

$K y=1.249$ より $K=1.249 / 0.331=3.8$

すなわち温度上年より求めた $K$ と大体一致してい ว.

(1)：環状層に扮いて $\left(c_{p} \Delta t / Q\right)_{m}=0.44$ を示す $K$ の值は同様に文献 (4) Fig. 5 より $K=18$ をうる。し

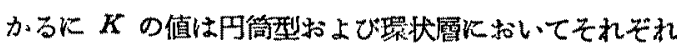

$$
\begin{aligned}
& K(\mathrm{H})=k^{\prime} R^{2} \rho c_{p} / \lambda \\
& K\left({ }^{2}\right)=k^{\prime}\left(r_{2}{ }^{2}-r_{1}{ }^{2}\right) \rho c_{p} / \lambda
\end{aligned}
$$

反応速度 $k^{\prime}$ は雨菱㽡の温度が大畧同一であるからー 定とみなしろるのて

$$
\frac{K \text { (1) }}{K(\text { (P) }}=\frac{18}{4.0}=\frac{r_{2}^{2}-r_{1}^{2}}{R^{2}}-\frac{8 r_{1}^{2}}{R^{2}}
$$

ゆえに $r_{1}=\sqrt{18 /(4)(8 ;} \cdot R=0.75 R=0.0199[\mathrm{~m}]$ すなから円筒型の半径 $R$ とすれは $r_{2} / r_{1}=3$ の環状 層では $r_{1}=0.75 R, r_{2}=2.25 R$ にすればよいことにな る。

ここで壁境膜の影敏 (b) について考える。女献 (4) の（29）式より円筒型，環状㬝に扣いてbは沬それぞれ $b($ 円 $)=1 \Re(R e \cdot d / D)^{-0.87} \fallingdotseq 16$ 


$$
\begin{aligned}
& b_{e g(\sin )}=127(\operatorname{Re} \cdot d / D)^{-0.87} \\
& =127\left\{\frac{(94.7)(0.006)}{(0.0529)(2.25-0.75)}\right\}^{-0.87} \\
& =22.9
\end{aligned}
$$

すなかち上の計算で梳円型では $b=16$ ，璒状層では $b=23$ であるすのを $b=\infty$ として計算したのである。 しかし b の値が有限のときは壁の抵抗が無視できない ので伝熱が悪く $K$ の值はいずれる小さくなるはずであ る。正確汇はるちん（13）式などの計算より得られる が，これを反応を伴わないときの数值（交献(4)の Fig. 1) 加大界の $K$ を推定してみる。すなから Fig.1 よると $r_{2} / r_{1}=3$ のとき $b=20$ と $b=\infty$ で同一の温度 低下を示すためには $\gamma(20) / y(\infty)=0.8 / 0.6$ でなければ ならない，ところが一方 $K$ は仮定より $c x=K y$ であ って同一反応を行うときは $K y$ の棈は一定である。こ のためには $K_{20} / K_{\infty}=0.6 / 0.8$ である必要がある。(y が增し $K$ が減少するためには

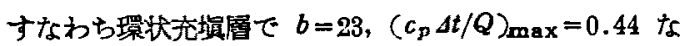
る $K$ の值は $K_{23}=(18)(0.6) /(0.8)=13.5$ である。円 筒型のときは同梯にして文献 (1) Fig. 2.6 より $b=16$ の $K$ の值は $K_{\mathrm{s} 6(\mathrm{P})}=4.0(0.37) / 0.4=0.37$ をうる。

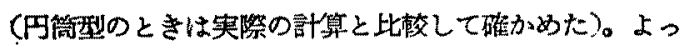
でを考慮したときは，

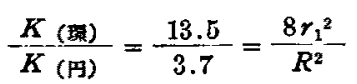

ゆ六に $r=0.675 R=0.0179[\mathrm{~m}]$

すなわら $b=\infty$ と考えたときより $10 \%$ \%さくせ视ば ならぬ。正しくは試行法で再計算を要す。

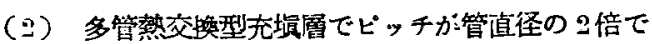
ある場合は交献 (4) よりその温度分布は $r_{2} / r_{1}=2.10$ な る外部冷却式と近似しうる。Fig. 5 よりこの場合の $\left(c_{p} \Delta t / Q\right)_{\max }=0.44$ を示す $K$ の值は $K=5.8$ であ D. $\alpha_{0} \tau \tau$

$$
\frac{K(\xi)}{K(\text { (3) }}-=\frac{5.8}{4.0}=-\frac{\left\{(3.10)^{2}-1\right\} r_{0}^{2}}{R^{2}}=\frac{3.4 r_{0}^{2}}{R^{2}} .
$$

江江 $r_{0}=0.653 R=0.0173[\mathrm{~m}]\left(2 r_{0}\right.$ 江冷却管外 径)

このときる $b_{e Q}=26.7$ となりこれで補正すると，

$$
K_{26}=5.8(0.5) /(0.65)=4.9
$$

$\Sigma o \tau$

$$
\frac{K(\xi)}{K(\mathrm{~m})}=\frac{4.9}{3.7}=\frac{3.4 r_{0}^{2}}{R^{2}}
$$

$r_{0}=0.624 R=0.0165[\mathrm{~m}]$

すなわち直径 $33 \mathrm{~mm}$ の管を用5ればよいことになる。 (3) 最高温度上年を $40^{\circ} \mathrm{C}$ におさえるとき，

出吅平均温度を $\Delta t_{m}=480+40 / 2=500^{\circ} \mathrm{C}$ 々仮定方 ると反店平衡は $95.6 \%$ であるから,

$$
\left(\frac{C_{p} \Delta t}{Q}\right)_{\max }=\frac{(0.245)(40)}{(0.956)(43.5)}=0.236
$$

これに対する $K$ の㯰は交献 (4)の Fig.5 より $b=\infty$

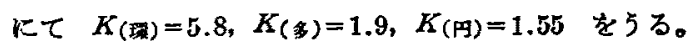
ただしこのときは平均温度および粒子径か变るために 実験の場合とは反応速度る变化するはずでる。これに ついては交献 (2)にも示したが, 円筒型では $K=k^{\prime} R^{2 p}$ $c_{p} / \lambda$ である。ここに $k^{\prime}$ は反応速度恒数であるが，粒子 の活性表面に比例し，(すなわち粒子径汇反比例し空腺 来に関係する)また温度に対してはフルレニウスの式に したがうわけである，上って央験の場合上り任意の条件 の反応速度を求めるには，次式に上る。

$$
k e^{A \Delta T / R P^{2}} / d(1-j)=\left[k e^{A \Delta T / R T^{2}} / d(1-j)\right]_{\mathrm{exp}}
$$

空隙率 $j$ は粒径が $4 \mathrm{~mm}$ のとき $6 \mathrm{~mm}$ のときす同 一と考え，また平均渣度上昇を $\Delta T=\Delta t_{m} / 3$ と仮定する と.

$$
\begin{aligned}
& \frac{k}{k_{\exp }}=\frac{6}{4} \exp \\
& {\left[\frac{11500(40 / 3)}{1.99(480+20+273)^{2}}-\frac{11500(73.7 / 3)}{1.99(516+273)^{2}}\right]} \\
& \quad=1.365
\end{aligned}
$$

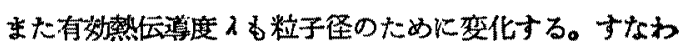
ち,

$$
\lambda / \lambda_{\exp }=(4 / 6)^{0.41}=1 / 1.18
$$

a) 円筒型充填署で実験の場合と温度上昇 $40^{\circ} \mathrm{C}$ と きとでは

$$
\begin{aligned}
& \frac{K}{K_{\exp }}=\frac{k^{\prime} r^{2} \rho c_{p}^{\prime \lambda}}{\left[k^{\prime} R^{2} \rho c_{p} / \lambda\right]_{\exp }}=\frac{k^{\prime}}{k_{\text {exp }}^{\prime}} \cdot \frac{\lambda_{\exp }}{\lambda} \frac{r^{2}}{R^{2}} \\
& \quad=(1.365)(1.18) \frac{r^{2}}{R^{2}} \\
& \text { ここで } K=1.55, K_{\exp }=4.0, R=0.0529 / 2 \text { を代入 }
\end{aligned}
$$
すると

$r(\mathrm{\oplus})=\sqrt{1.55 /\{4.0(1.18)(1.365)\}} \cdot R=0.012[\mathrm{~m}]$

触媒㬝の長さは， $n=0.674 / 0.956=1-e^{-\kappa y}$ より

$K y=1.187 \quad$ よって $y=1.187 / 1.55=0.766$

$\left[\equiv \pi \lambda x / W c_{p}\right]$

こで

$$
W=4.48[2(0.013) / 0.0529]^{2}=1.075 \mathrm{~kg} / \mathrm{hr}
$$$$
\lambda=0.465(4 / 6)^{0.41}=0.394
$$

ゆ之に $y=0.766=\pi(0.394) x /\{1.075(0.245)\}$

ゆえに $x=0.163[\mathrm{~m}]$

すなわち円筒型では直径 $26 \mathrm{~mm}$, 圈長 $163 \mathrm{~mm}$ でよ wa

b）環状層では

$$
\frac{\left.K_{(1)}\right)}{K_{(\text {( ) }}}=\frac{5.8}{4.0}=(1.365)(1.18) \frac{8 r_{1}^{2}}{R^{2}}
$$




$$
\begin{aligned}
\therefore r_{1} & =0.335 R=0.0089[\mathrm{~m}] \\
r_{2} & =1.0 R=0.02645[\mathrm{~m}]
\end{aligned}
$$

触媒原の長さは円筒型と同样にして

$$
\begin{gathered}
K y=1.187 \quad K=5.8 \text { \&り } y=0.205, \\
W=4.48\left(8 r_{1}^{2}\right) / R^{2}=4.03[\mathrm{~kg} / \mathrm{hr}] \\
y=0.205=\left\{\pi(0.394) i_{i}^{\prime}(4.03)(0.245)\right\} x \\
\therefore x=0.164[\mathrm{~m}] \\
\text { c) 熱交換型で }
\end{gathered}
$$

$$
\begin{aligned}
& \frac{K(\text { 外 })}{K(\text { 的 }}=\frac{1.9}{4.0}=(1.18)(1.365)-\frac{\left\{(2.10)^{2}-1.0\right\} r_{0}^{2}}{R^{2}} \\
& \therefore r_{0}=0.295 R=0.0078[\mathrm{~m}] \\
& K y=1.187, \quad K=1.9 \quad \text { より } y=0.625 \\
& W=4.48(3.4) r_{0}^{2} / R_{0}=(4.48)(3.4)(0.295)^{2}=1.32 \\
& \therefore \quad y=0.625=\frac{\pi(0.394)}{1.32(0.245)}-x \\
& \therefore x=0.164[\mathrm{~m}]
\end{aligned}
$$

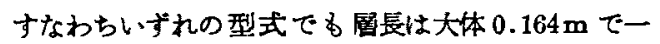
定であるがこれ恃応速度と同一としているから当然の ことである。るちろんこの計算ですbを考える方が正
しい。円筒型を例にとると

$$
\begin{aligned}
b & =127(\operatorname{Red} / D)^{-9.87}=127\left\{\frac{(63.3)(0.004)}{(0.013)(2)}\right\}^{-0.87} \\
& =9.2 \\
b & =9.2 \text { で }\left(c_{p} \Delta t / Q\right)_{\max }=0.286 \text { で } K=1.22 \text { て }
\end{aligned}
$$

あり実験では $b=16, K=3.7$ であったから

$$
\begin{aligned}
& \frac{K}{K_{c}}=(1.18)(1.365) \frac{r^{2}}{R^{2}}=1.20 \\
& \therefore r=0.45 R=0.0119[\mathrm{~m}]
\end{aligned}
$$

すなわち a) の場合に比してやや小さくせねばならね ことがわかる。この例よりさらに温度を小さくしようと すれば塔径 $D$ が粒子径 $d$ 下近付き，粒子の充㘿不 均一であり理論式が一致しなくなるから注意を要する $D / d>4$ 位でなければ無理である。

\section{女献}

1) 八田, 前田: 化学工学 12, 56 (1949)

2) 前田, 川添: "

3) 前田, 㦘 : " 15, 312 (1951)

4) 前田, 川添: * 18, 279 (1954)

\section{大型触媒反応塔内の温度分布}

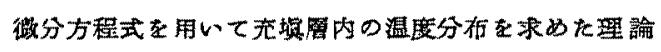

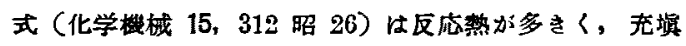
周内の温度伡容籁团が㹟いるのに適用せられるが，実際

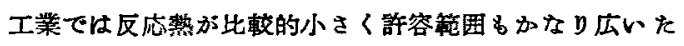

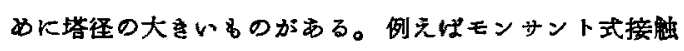

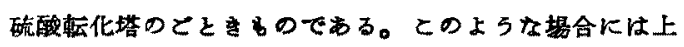
記の理論式の適用, あるいは簡羊烤えて断熱といら考

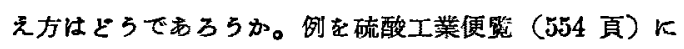
求めて計算してみる。すなわち $7 \% \mathrm{SO}_{2}$ は $5 \mathrm{~mm}$ 淔径 ベナジゥム触媒充洗した第 1 塔に $400^{\circ} \sim 405^{\circ} \mathrm{C}$ でり 70 80\% 化されて $580^{\circ} \sim 590^{\circ} \mathrm{C}$ で出る。(第2塔では

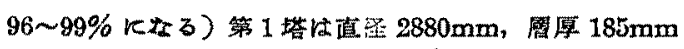
で能力は $98 \%$ 硫酸 $50 \mathrm{t} /$ day てむる。部算䋨果は

全ガス量: $9528 \mathrm{~kg} / \mathrm{hr}$., 有奻繁伝溥率 $\lambda=0.43 \mathrm{Kcal} / \mathrm{m} \mathrm{hr}{ }^{\circ} \mathrm{C}$

出口Kすけ $y=\pi \lambda x / G C p=0.00022$

生た反応率上り求めたKは9450で上記交献の小型装

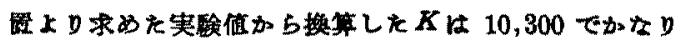

一教している。それで閏趣の第 1 塔の温度分布は $K=$ $10,000 y=0.0002$ 位での盟度分布を知れげよい。この堤 合はyの值が非常に小さレので理論式のベッャル函数に まりる $n$ の值を相当大きくとらね收崄しない。すなか $5 n=40$ ではまだ十分でないが中心温度 $t_{c}$ と $r / R=9 / 10$ の点の温度 $t$ 乙比較すると $\left(t_{\mathrm{c}}-t\right) / t_{e} \times 100 \div 0.2$ 位K

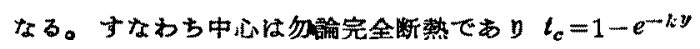
の形で盜度は上昇するが $\sim 0.0005$ で 0.2\%しか中心の温度分布上り偏位しない。 （との外側を流れる流量仕䄪 $20 \%$ である）すなわ完 全断熱とみてる差支えあるまいと思われる。る5少し反 沁速度が幄いか，塔径の小さい場合で $K=$ こ00 位になる。 そ, 中心温度飞の很差 $\left(t_{c}-t\right) / t_{c}$ は

$$
y=0.002, \quad y=0.004, \quad y=0.006 \quad y=0.008
$$
К拮いてそれぞれr $/ R=9 / 10$ では $3 \%, 17 \%, 28.4 \%$, $45 \%$ そな $r / R=7 / 10$ では $0.0 \%, 1.0 \%, 2 \%, 2.5 \%$ そなって $\boldsymbol{y}=0.004$ より大すい $\boldsymbol{y}$ K対しては断熱とは 考无得なくる。

(前田) 